\title{
A MONETARY POLICY RULE BASED ON FUZZY CONTROL IN AN INFLATION TARGETING FRAMEWORK
}

\author{
Jaromír Kukal, Tran Van Quang*
}

\begin{abstract}
Today inflation targeting regime is often used to conduct monetary policy in most developed economies. In this regime, a central bank manipulates its key interest rate to steer an economy to the objectives it wants to achieve. To implement its monetary policy, Taylor rule is claimed to be a quantitative tool used as a guide for setting interest rate in response to the state of the economy. Despite its widespread popularity, the Taylor rule is just an orientational guidance at best and cannot be followed strictly since it would be against the common practice of conducting monetary policy of most central banks. Therefore, we propose a new rule for inflation targeting monetary policy based on fuzzy control technique. This rule seems to be able to quantify those widely accepted qualitative knowledge on monetary policy. Further, the policy derived by this rule also better captures the common behaviour of central banks. We verify this rule on the monetary policy conducted by the Czech National Bank in the period from 2000 to 2011 . We also compare the result of this rule with the results obtained by implementing monetary policy by some other alternative rules.
\end{abstract}

Keywords: monetary policy rules, Taylor's rule, Fuzzy control rule, $2 \mathrm{~W}$ repo rate

JEL Classification: E52, E58

\section{Introduction}

Nowadays monetary policy is no longer considered to be a universal tool to achieve multiple economic and social objectives: mild and stable inflation, high growth, low unemployment and stable exchange rates. On the contrary, the agreement among theorists as well as practitioners is such that it should be transparent and its main focus should be put on the stability of the national currency. One way how to implement such monetary policy is inflation targeting regime (see Bernanke et al., 1999). The primary objective of a central bank is to maintain price stability in the economy and in the inflation targeting regime, it is to keep inflation as close to its target as possible. The central bank can support economic growth and help to keep high employment in the economy. But these objectives are secondary. Reaching them must not compromise its primary goal. Similarly, today the instrument used to achieve these objectives has also changed. Unlike the previous belief that the stability of national currency can be reached by controlling the money stock in the economy as Friedman (1968) suggested, now central banks shift

* Author Tran Van Quang is grateful for the financial support of Czech Science Foundation in the framework of Grant P402/12/G097. Author Jaromír Kukal acknowledges the financial support of Grant SGS 11/165/OKH4/3T/14 CTU in Prague. 
the emphasis on controlling the key short-term interest rate. In fact, it is the only option remained to the central banks.

Qualitatively, the monetary policy rule in the short-term interest rate setting is very simple and well-understandable. If the inflation in an economy is high, then the central bank increases its short-term rate and through a transmission mechanism it reduces the aggregate demand and lowers the price level in the economy which brings the inflation back to a desirable level. On the opposite side, when the inflation in an economy is low, then the central bank lowers its short-term rate and through a transmission mechanism it boosts the aggregate demand and inflates the price level in the economy which increases the inflation to a desirable level and prevents the economy from deflation. While no one disputes the validity of this interest rate rule, there is a serious problem we have to face: how to quantify the size of the interest rate to be set.

For this purpose, several such interest rate rules have been proposed and the most popular rule is the so called Taylor's rule. Though the Taylor's rule and its modifications well reflect the practice of interest rate setting of most central banks, the rule itself raises two other problems. First, Taylor's rule contains several parameters. As a result, we have to ask what should be the values of these parameters. So far they are assigned to such values which makes them fit with the data. Second, Taylor's rule is a linear function of the deviation of inflation from inflation target value and the output gap. Therefore, the higher the deviations are, the larger the change in interest rate should be, and following the rule may lead to wild changes in interest rate. This is a sharp contrast to common behaviour of most central banks in the world which always try to smooth the changes in interest rates.

To overcome these two problems, we suggest a new approach. From the regulation point of view, monetary policy in the inflation targeting regime is a traditional control problem. When manipulating the interest rate, a central bank tries to steer the real inflation to its targeted value and the economic growth towards its potential. As the underlying processes are not fully known and well mathematically defined, we cannot use the standard control tools. Also in such cases, fuzzy control can be an effective alternative. That is why we will apply it to monetary policy to create a rule for setting interest rate in inflation targeting regime. After that, we will verify this rule on the case of the Czech economy and compare it with the actual monetary policy conducted by the Czech National Bank (CNB). We believe that the approach we propose can be a useful tool for central bankers to quantify the magnitude of interest rates to be set when they conduct monetary policy. The rest of this paper is structured as follows: in Section 2 we will highlight some monetary policy rules which have been suggested so far. Then in Section 3 we will explain some basics of fuzzy logic and fuzzy control. After that, in Section 4, the fuzzy control approach is applied to monetary policy. In Section 5, we will verify how monetary policy should have been conducted by using the fuzzy control approach for the last decade in the Czech Republic and the results will be compared to how it has been actually run by the Czech National Bank in this period of time. Finally, some concluding remarks will be made in the Conclusion. 


\section{Monetary Policy Rules}

Today, central banks of most developed economies are independent which means that they can use all available instruments to conduct monetary policy without instruction, guidance and interference from political institutions. They are allowed to do so because it is the best way for them to achieve their primary objective: to keep the price level in the economy stable. The independence of central banks does not mean that they can do whatever they wish. Quite the opposite, it makes them accountable for the monetary policy mandated to them and transparent in their policies. Transparency in monetary policy helps to evaluate the performance of central banks and increases their effectiveness. It also helps to reduce the uncertainty in an economy. Independence, accountability and transparency are three fundamentals which lay out the foundation for inflation targeting regime. In this regime the primary goal of monetary policy is to maintain inflation low and stable. The conduct of monetary policy is such that the central bank sets a near future target for inflation and manipulates its policy short-term interest rate to steer the real inflation in the economy towards this value. The rule is clear: the key interest rate will be changed if there is a (possible) deviation of inflation from the target value. The only remaining problem is how much it should be changed. Knowing the rule how to set the interest rate is desirable not only for the central banks, but also for other market participants as they know what they can expect from the central banks.

Economists have been trying to set a quantitative rule for monetary policy to reach its objectives. Wickselll (1936) was the first who suggested that the main objective of a central bank should be to keep price level in the economy stable. Theoretically, price stability can be achieved if the interest rate is always equal to the natural interest rate. But the natural interest rate is an unobservable quantity therefore it is diffcult for the central bank to do it. He proposed a very simple rule which has become a common economic wisdom. The rule states that if prices increase, then the central bank ought to raise the interest rate, if prices fall, the interest rate should be lowered and the interest rate should be kept unchanged if prices stay put. This simple rule dealing with inflation by manipulating interest rate can be formalized as follows:

$$
i=\beta \pi,
$$

where $i$ is the interest rate, $\pi$ denotes inflation rate, and $\beta$ is a parameter. This rule was very simple which was its advantage. The disadvantage of this rule was that it did not take into account the development of other economic variables and as a result, it did not attract much attention of policy-makers.

Another simple policy rule was proposed by Friedman (1968). The rule comes from the quantity theory of money:

$$
M V=P Y,
$$

where $M$ is the money supply, $V$ is the velocity of money, $P$ is the price level and $Y$ denotes the real output. Taking logarithm of (2), we get: 


$$
m+v=p+y,
$$

where $m, v, p$, and $y$ are the logarithms of $M, V, P$, and $Y$, respectively. Lagging this equation by one period, we have:

$$
m_{-1}+v_{-1}=p_{-1}+y_{-1} .
$$

Subtracting the lagged equation from the unlagged one, after a small rearrangement, we get:

$$
\Delta m+\Delta p=\Delta y+\Delta v,
$$

Provided that the velocity of money is stable, according to Friedman, it would be suffcient to keep the inflation in the economy at rate $\pi^{*}$ and the potential growth rate $\Delta y^{*}$ if the growth rate of money is held at rate $\Delta m=\Delta y+\pi^{*}$, since $\pi^{*}=\Delta p$. The advantage of this rule is that it does not require any other information than the potential growth rate and the target value of inflation. The flip-side of the rule is that in the fractional reserve banking system, the central bank cannot control the money stocks in the economy as well as that the demand for money is not stable for many reasons.

To overcome the disadvantages of the two previous rules, Taylor (1993) proposes a rule which takes into account the new trend. This trend is that today, central banks use the policy interest rate as the only instrument to implement their monetary policy and the objective of monetary policy is twofold: to keep price level stable and to support economic growth. According to Taylor, the policy interest rate $i$ should be a function of the real interest rate $r$, inflation $\pi$, the deviation of inflation from its target value $\pi^{*}$, and the deviation of output $y$ from its potential value $y^{*}$. Formally, the Taylor original rule is as follows:

$$
i=2+\pi+\frac{1}{2}(\pi-2)+\frac{1}{2}\left(y-y^{*}\right)
$$

In his original rule, the inflation target $\pi^{*}$ and the real interest rate $r$ are set to be equal to 2 . The rule links interest rate with inflation and economic activity and makes both Wicksell's rule and Friedman's rule as special cases. The original rule may fit well with the USA data from period 1980 - 1990, but as time proceeds, it needs some modification. Orphanides (2003) suggests a generalization of the original rule as follows:

$$
i=\theta_{i} i_{-1}+\left(1-\theta_{i}\right)\left(\pi^{*}+r^{*}\right)+\theta_{\pi}\left(\pi-\pi^{*}\right)+\theta_{y}\left(y-y^{*}\right)
$$

where $\theta_{i}, \theta_{\pi}$, and $\theta_{y}$ are parameters. This generalization extends the original form by a term $i_{-1}$ and adjustment coefficient $\theta_{i}$ which takes into consideration a common behaviour of central banks which tend to smooth the key interest rate rather than let it jump wildly. Taylor's rule allows central banks to pursuit a wide range of monetary policies. ${ }^{1,2}$

1 There are many similar extensions of the original Taylor rule, a similar one was proposed by Woodford (2001).

2 McCallum has developed a similar rule targeting the monetary base. As the instrument used in this rule is rather non-traditional, the rule has not attracted so much attention. 
The Taylor rule is a valuable guidance for policy-makers. Nevertheless, it includes several parameters, to which certain values must be assigned. For example, originally, Taylor assumes that $\theta_{\pi}=\theta_{y}=\frac{1}{2}$, and the policy generated by the rule well coincides with the actual policy of the American central bank (FED) in the period 1980-1990. Now, in order to preserve this agreement with data, other numbers are assigned to these parameters. By that way, the policy does not depend on values of economic variables generated by the economy itself, but also on the values of parameters of the rule. This ad hoc assignment makes the Taylor rule less as a rule than it should be. As Taylor (1993) himself admits: "operating monetary policy by mechanically following a policy rule like equation (4) is not practical" and the result of the rule can serve only as an input for the central bank decision making process. Svensson (2003) explains it in the similar way as he says the rule is best understood as a commitment to a targeting rule rather than an instrument rule. So we are back in where we have been before. Further, this problem has been confirmed by many empirical evidences which have shown deviations of the actual monetary policy from those derived from Taylor rule and its variants as Orphanides (2001), Arlt and Mandel (2012) have pointed out.

There is also another issue with the Taylor rule which has not often been mentioned in the literature yet. Either in its original form or in the generalized one, it is a linear function of the deviation of actual inflation from its targeted value and the deviation of the product from its potential. If these deviations are large, the corresponding change in interest rate must also be large. Following the rule strictly would lead abrupt changes in interest rate. But it is not a pattern that the central banks want to follow. On the contrary, they tend to change it smoothly and make small changes in multiples of a quarter of a percentage point instead of a big one. For example, in the Czech Republic, the largest change the Czech National Bank has made since 2000 was three quarters of a percent. As a result, Taylor's rule seems to be another qualitative rule than a quantitative one with practical use. Therefore, there is still a need of how to quantify the general monetary rules. In the next section we will propose a new approach to enumerate the monetary policy rule which, on the one hand, can capture common behaviour of central bankers. On the other hand this rule can avoid the over-dependence on the values of the parameters which are subjectively selected to fit the data.

\section{Fuzzy Logic and Fuzzy Control}

In many real-life cases, the objective of a control problem can be mathematically well defined and precisely formulated. In these cases the optimal control strategy is the solution of optimization problem and the corresponding values of controls can be found. But it is not always the case. In many other situations, one can only rely on the experience of experts which is not easily quantified in any exact formula. For example, if we want to control the temperature inside of a room and for some reason the underlying thermodynamic process is not known, then we can do it the following way. If it is hot in 
the room, then we should open the window or turn up the air-conditioner in the room. If it is cold in the room, then we should close the window or turn down the air-conditioner. If it is too hot inside, the window should be widely opened, if it is not so hot, then just ajar and so on and so forth. The control is expressed in a form of natural language, which, on the one hand, is very easy to understand, but on the other hand, it is quite vague. Fuzzy control is a control method which changes these vague rules into the exact control strategy. A fuzzy control process as described above consists of four parts. The first part is the fuzzification which changes the real inputs to fuzzy values. The second part is a set of rules expressing common theoretical knowledge on what should be done in order to reach the set target. The third part of a fuzzy controller is a rule combination which reconciles the contradicting rules to choose the best action to be done in order to reach the goal of controlled process. The last part is defuzzification which converts the fuzzy values back to real values of the controlled process.

\section{Fuzzification}

Fuzzification maps a value $v$ of quantity $V$ into interval $[0,1]$, thus formally:

$$
\mu: V \rightarrow[0,1]
$$

The mapping is called the membership function which measures a degree of membership of $v$ to a certain set (category). Unlike a conventional set, where the degree of membership of any object in the set is either 0 or 1 , the membership function can be Z-shaped, triangular or trapezoidal and it can be any value between 0 and 1. For fuzzy sets (A and B), the following operators are defined:

- fuzzy intersection operator $\wedge$ (AND connective):

$$
\mu(A \wedge B)=\min \{\mu(A), \mu(B)\},
$$

- fuzzy union operator $\vee(\mathrm{OR}$ connective):

$$
\mu(A \vee B)=\max \{\mu(A), \mu(B)\},
$$

- fuzzy complement (not operation):

$$
\mu(\operatorname{not} A)=1-\mu(A) .
$$

\section{Fuzzy rules}

Fuzzy rules come from the experience of experts and consist of IF - THEN statements which are characteristic to human thinking and perception. Each if-then statement with an antecedent and a consequent forms a fuzzy proposition. The antecedent can also contain a combination of propositions connected by logical operators AND and OR. For example, a rule can look like this: 


\section{IF $v_{1}$ is $A_{1} \ldots$ and $v_{\mathrm{i}}$ is $A_{\mathrm{i}}$ THEN do $B_{1}$.}

\section{Rules combination}

Since there is a set of experts' rules, we have to determine the grades of fulfillment of each rule and connect them together by using AND connective and OR connective. Then we evaluate the consequent of each individual rule either by using the min implication (more often) or the product implication. Finally, all partial individual consequences are aggregated into an overall result.

\section{Defuzzification}

The output from the previous part are fuzzy numbers presenting the final consequent from a set of rules of form if - then. These fuzzy numbers need to be converted back to a crisp number as the value of the control should be set. There are many ways to do so, but the most often used one is the so called center of gravity method (COG). The sought crisp value is the centroid of the area under the graph of the membership function of the output set. Formally, the center of gravity is defined as average value as follows:

$$
c=\frac{\int_{V} v \mu(v) \mathrm{d} v}{\int_{V} \mu(v) \mathrm{d} v}
$$

In practice, the discrete version of this formula is mostly used. From the construct of a fuzzy controller, a process, to which a fuzzy controller should be applied, can be divided into 3 stages: mapping stage, processing stage and regulation stage. In the first stage, the crisp inputs need to be obtained, then they are processed in the second stage and in the final one the control is set to the value as the output of the second stage to reach the desired state. To find more on fuzzy logic and fuzzy control, see Novák (2000) and Jantzen (2007).

\section{The Application of Fuzzy Control to Monetary Policy}

In this section, the fuzzy control principle presented in the previous part is applied to monetary policy. We assume that a central bank conducts its mandated monetary policy in the inflation targeting regime. In this regime, the objectives of the central bank are prioritized. The highest priority is awarded to keeping price stability in the economy, i.e. managing inflation close to the preset target. Other objectives are subordinate to the first one. In this work, we assume that the other objective of the central bank is to support economic growth. In order to achieve its primary goal, the central bank sets the target value for inflation. As far as the economic growth is concerned, the optimal growth rate is the growth rate of the potential product of the economy. The optimal policy of the central bank is to keep both the actual inflation and economic growth rate roughly around these two values. The central bank can achieve these objectives by properly changing 
its instrument interest rate. The central bank either can react to the current state of the economy or its policy can be forward-looking that is, its policy responds to the near future state of the economy. In latter case let's assume that it has reliable forecast on the state of the economy in the near future.

\section{Fuzzification}

Let's suppose that the central bank makes its target value for inflation equal to $2 \%$ and the growth rate of the potential product of the economy is 3\%. The central bank also gets the information about the current state of the economy, namely about the current inflation rate and the actual growth rate. Using the fuzzy control approach, first the central bank must convert these crisp numbers on inflation and economic growth into fuzzy numbers. It is done as follows. First the membership function for inflation and economic growth needs to be constructed. Inflation can be high, low and just right. As the target value is $2 \%$, the degree of just rightness of inflation is 1 if the actual inflation lies in the interval $(1.5,2.5)$. The membership value of inflation decreases towards 0 when the actual inflation in the economy falls towards 0.5 and rises up to 3.5 , respectively. The membership value is 0 if the actual inflation is less than 0.5 or greater than 3.5. The membership function of inflation in the case it is just right has a trapezoid shape. With respect to the target value, the degree of lowness of inflation is 1 if inflation is less than 0.5 . This value decreases towards 0 when the actual inflation increases towards 1.5. The degree of lowness of inflation is 0 when the actual inflation is greater than 1.5. The membership function of the lowness of inflation has the Z-shape. The degree of highness of inflation is 0 if inflation is less than 2.5. This value increases towards 1 when the actual inflation increases towards $3.5 \%$. The degree of highness of inflation is 1 when the actual inflation is greater than $3.5 \%$. The membership function of the highness of inflation has an inverse Z-shape. The membership functions of all three cases (high, low and just right) of inflation are shown in Figure 1

Figure 1

The Membership Function for Inflation

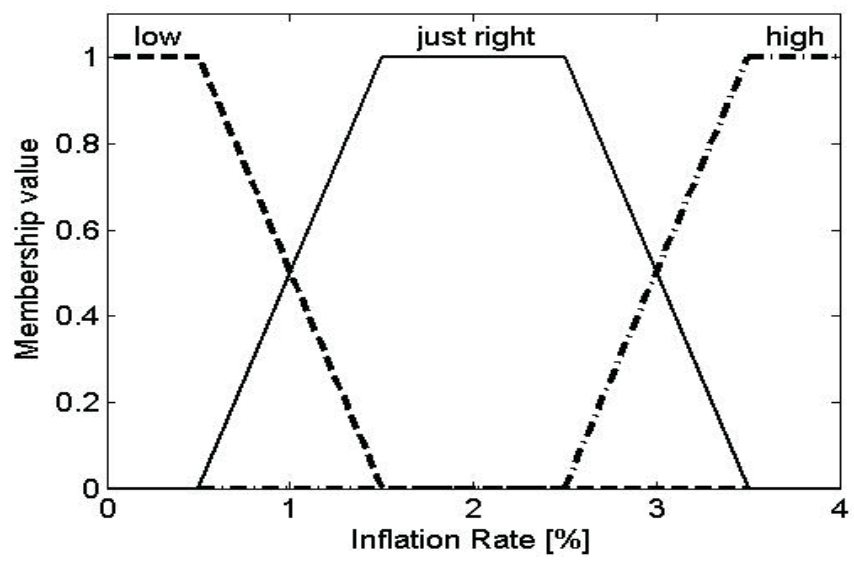


By the same token we construct the membership functions for all three cases of economic growth with the value for growth rate of potential product equal to 3\%. The membership functions of all three cases (high, low, and just right) of economic growth are shown in Figure 2.

\section{The rules}

In accordance with monetary theory (Walsh, 2010) and with respect to the objectives of the central bank, there are only two rules to be followed:

Rule 1: IF inflation is high, THEN the interest rate is to be increased which reduces the aggregate demand in the economy through transmission mechanism and as a result it tames inflation. On the contrary, IF inflation is low, THEN the interest rate is to be lowered which boosts the aggregate demand in the economy through transmission mechanism and as a result, it increases inflation and prevents the economy from deflation.

Rule 2: IF the growth rate is high, THEN the interest rate should be increased to prevent the economy from overheating. IF the growth rate is low, THEN the interest rate should be reduced to support economic growth. IF the growth rate is just right, THEN the interest rate is to be kept unchanged.

Figure 2

The Membership Function for Economic Growth

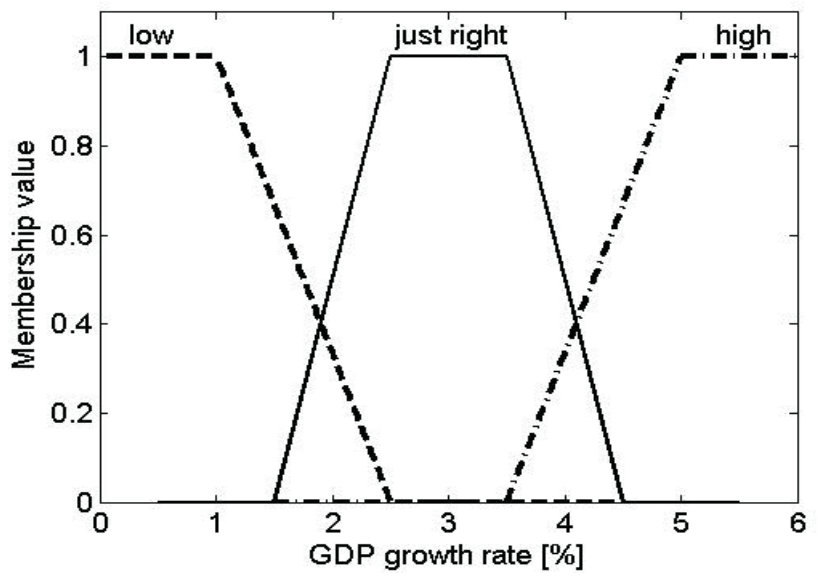




\section{Combination of rules}

As inflation as well as the economic growth can be high, low and just right, together we have 9 different combinations from each state of these two variables. Since the priorities of the central bank are hierarchized, and keeping the price level in the economy is its primary objective. Therefore, at times implementing rule 2 may lead to a violation of its highest priority. As a result, monetary policy in the inflation targeting framework can be conducted in these combined states in the following way:

- IF inflation is low and the GDP growth rate is also low, THEN the central bank reduces the instrument interest rate to support economic growth because lowering interest rate is in line with both 2 rule and does not compromise the primary objective of the central bank.

- IF inflation is low and the GDP growth rate is just right, THEN the central bank can reduce its interest rate. Supporting economic growth in this case does not endanger the inflation target.

- IF inflation is just right and the GDP growth rate is low, THEN the central bank can lower its interest rate to support economic growth. Even in this case, boosting the aggregate demand may not worsen the inflation perspective.

- IF inflation is high and the GDP growth rate is also high, THEN the central bank increases its policy interest rate. Raising its rate, the central bank can achieve both its objectives at once.

- IF inflation is high and the GDP growth rate is just right, THEN the can decrease its interest rate to meet its inflation target because price stability objective is superior to economic growth objective.

- IF inflation is just right and the GDP growth rate is high, THEN the central bank raises its rate unchanged because excessive aggregate demand may affect inflation in the near future.

- IF inflation is just right and the GDP growth rate is also just right, THEN the central bank keeps the rate unchanged because both objectives are already achieved.

- IF inflation is low and the GDP growth rate is high, THEN the central bank keeps its rate unchanged because the high economic growth may not originate from an excessive demand, the central bank can wait and see.

- IF inflation is high and the GDP growth rate is low, THEN the central bank can keep the its rate unchanged because low economic activity may pull the inflation rate back to the lower level. These combined rules are summarized in Table 1.

Table 1

Monetary Policy Rules

\begin{tabular}{|l|l|l|l|}
\hline & Low Inflation & Just Right Inflation & High Inflation \\
\hline Low Growth Rate & decrease & decrease & do not change \\
\hline Just Right Growth Rate & decrease & do not change & increase \\
\hline High Growth Rate & do not change & increase & increase \\
\hline
\end{tabular}


Needless to say that the interest rate cannot be negative. If it is already close to zero, the central banks should look for another measure to achieve its objectives (the so called balance sheet instrument).

From Table 1, it is clear that the central bank lowers its key interest rate either when inflation and growth rate are low or when inflation is low and growth rate is just right or when inflation is just right and growth rate is low. On the other hand, it should increase its key interest rate either when inflation is high and growth rate is also high or when inflation is high and growth rate is just right. Finally it does not change its key interest rate in the remaining situations. Formally we have as follows:

$$
\mu(D E C R)=\mu\left(\left(I^{L} \wedge G^{L}\right) \vee\left(I^{L} \wedge G^{J R}\right) \vee\left(I^{J R} \wedge G^{L}\right)\right) .
$$

Similarly, the increase of the interest rate happens when either inflation and growth rate are high or when inflation is high and growth rate is just right.

$$
\mu(I N C R)=\mu\left(\left(I^{H} \wedge G^{H}\right) \vee\left(I^{H} \wedge G^{J R}\right) \vee\left(I^{J R} \wedge G^{H}\right)\right)
$$

And the interest rate is kept unchanged when both previous cases do not happen, which means:

$$
\mu_{U N C}=1-\mu_{\mathrm{DECR}}-\mu_{\mathrm{INCR}}
$$

\section{Fuzzy interference and defuzzification}

Since there are nine possibilities inflation and GDP growth rate can fall into, the final rule for interest rate decision is a combination of some of these nine possibilities connected by operator OR. Each possibility is a situation in which inflation and economic growth are connected by operator AND. The central bank can either increase its key interest rate or lower it or keep it unchanged. The membership value of each possibility is derived from the corresponding membership value of inflation and growth rate. They are linked together first by operator AND for each possibility and possibilities are connected together by operator OR. For operator AND the max rule is used and for operator OR, the min rule is used to get an output fuzzy number. After that this number must be converted to a crisp number which is the size of the change of the key interest rate. In order to do so, the membership function for the interest rate change needs to be constructed. In accordance with the common practice of most central banks which tend to make a change of the interest rate at most of size of $1 \%$ for either direction, a decrease or an increase has the membership value of 1 if the size of a change ranges from $(-1,-0.5)$ and $(0.5,1)$, respectively. As the size of a change moves towards 0 , the membership value of decreasing and increasing also falls towards zero. If the size of a change of the interest rate is greater (less) than 0, the membership value for decreasing (increasing) the interest rate is 0 . The membership value for keeping the interest rate unchanged is 1 if the size of a change is 0 . The value gradually decreases towards 0 as the size of 
a change moves towards -0.25 and 0.25 , respectively. The membership value for keeping the interest rate unchanged is 0 if the size of a change is outside of interval $(-0.25,0.25)$ (see Figure 3 ). The resulting crisp value then is calculated by the center of gravity method (COG) proposed by Mamdani and Assilian (1975) which is the value of the abscissa of the center of gravity of the area below the membership function.

Figure 3

\section{Membership Function for Interest Rate Change}

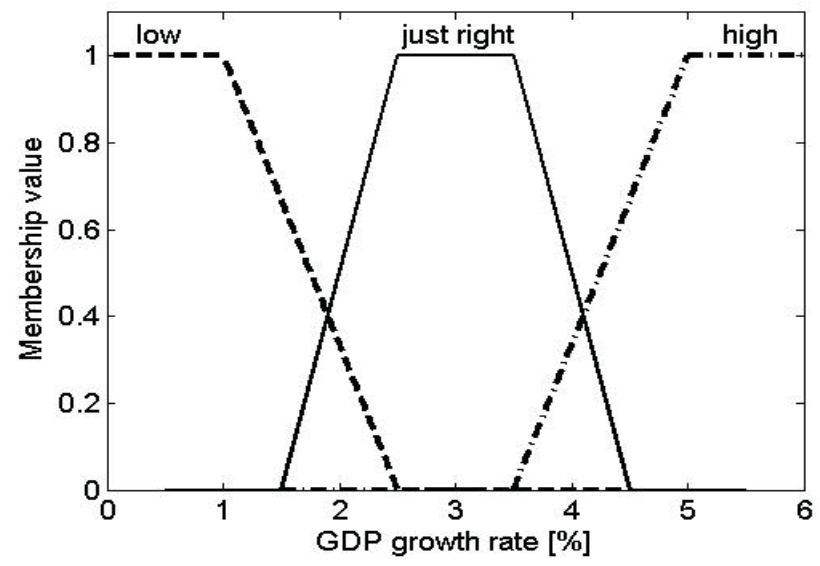

\section{An example}

Let's assume that the central bank has a reliable forecast indicating that in the mediumterm future the inflation rate will be $1.1 \%$ and the growth rate will be $1.8 \%$. The target value for inflation is $2 \%$. The potential long-run growth rate of the economy is $3 \%{ }^{3}$ Putting these numbers into the membership functions proposed in the previous section, we get the values of membership function for inflation: the degree of lowness $\mu_{I}^{L}=0.4$, the degree of just rightness is $\mu_{I}^{J R}=0.6$, and the degree of highness $\mu_{I}^{H}=0$. The values of membership function for growth rate are: lowness $\mu_{G}^{L}=7 / 15$, just right $\mu_{G}^{J R}=0.3$ and highness $\mu_{G}^{H}=0$. Substituting these values into (8), (9), and (10), and using the max and min rule, we get the membership values for decreasing the interest rate $\mu_{\mathrm{DECR}}=7 / 15$, the membership values for increasing the interest rate $\mu_{\mathrm{INCR}}=0$ and for keeping it unchanged $\mu_{\mathrm{UNCH}}=8 / 15$. The size of the change of the interest rate is $\mathrm{x}$ coordinate of the centroid of the shaded area shown in Figure 4. The crisp value of the change of the interest rate can be calculated by using formula 6 and the value is 0,233 . Since the central bank changes its key rate in multiples of a quarter percent, in this case it lowers the key interest rate by one quarter percent if the rate is not zero already. 
Figure 4

\section{Membership Function for Interest Rate Change}

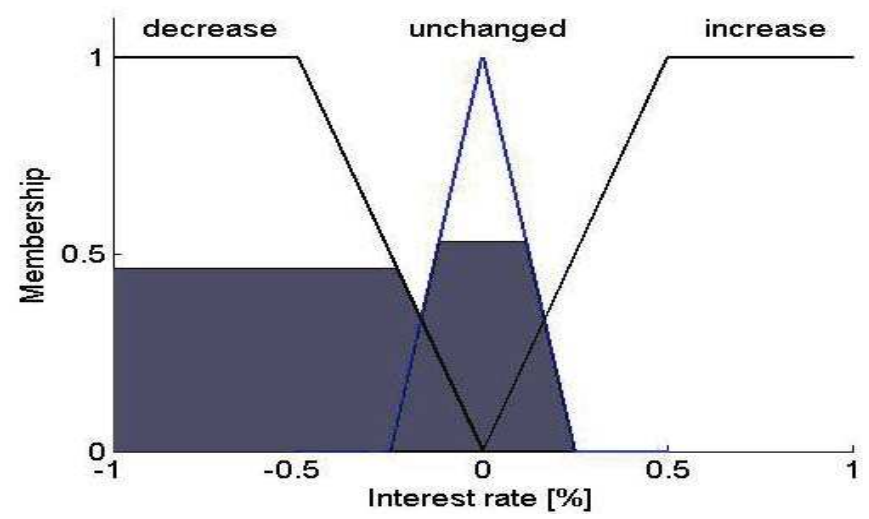

\section{The Verification of CNB Monetary Policy since 2000}

In the Czech Republic according to its constitution and Act No. 6/1993 Coll. on the Czech National Bank, monetary policy is mandated to the care of the Czech National Bank (CNB). The primary objective of the CNB is to maintain price stability in the Czech economy. At the same time, the CNB may support the general economic policies of the Czech government, basically in terms of economic growth, if its primary goal is not compromised. To achieve its objectives, the $\mathrm{CNB}$ have been using inflation targeting regime since 1998. In this regime, the CNB makes an explicit public announcement on the inflation target it wants to reach (for example, it is the inflation rate of $2 \%$ measured by CPI since the beginning of 2010) and by changing the key monetary policy interest rate $2 \mathrm{~W}$ repo rate, ${ }^{3}$ it steers the real inflation rate CPI towards its preset target. The decisions on the desired level of this rate are made by the CNB Bank Board and based on the current macroeconomic forecast and an assessment of the risks to its fulfillment.

In this part, with the use of fuzzy control approach explained in the previous part, we verify how monetary policy has been managed by the CNB through the change of the $2 \mathrm{~W}$ repo rate since 2000. Data on the price level and economic dynamics in the Czech Republic information on inflation are collected and published by the Czech Statistical Office (CSO). For our purpose we use quarterly data of these two variables. The Czech Statistical Office publishes, among others, a quarterly series of Consumer Price Indices. The inflation rate is calculated as a ratio of a current CPI index and the same index for four quarters before. ${ }^{4}$ To get the GDP growth rate, as CSO provides a series of

$32 \mathrm{~W}$ repo rate is the rate by which the CNB withdraws the excess liquidity from the market.

4 Strictly speaking, it is calculated as follows: $\pi_{t}=100\left(\frac{\mathrm{CPI}_{t}-\mathrm{CPI}_{t-4}}{\mathrm{CPI}_{t-4}}\right)$. 
quarterly year-on-year GDP-by-expenditures indices at constant prices, the rate is simply computed by subtracting 100 from the index. The development of inflation measured by CPI is shown in Figure 5. As it is shown, at the start of the last decade the inflation was relatively high due to the effect of the final stage of the transition period in the Czech economy, but basically it fell gradually in line with the target set by the CNB. After that, the inflation dropped towards zero as a result of the declines of food prices and import prices which were attributable to an annual decline in prices of raw materials (especially oil and gas), the low inflation in the Czech Republic's major trading countries, and to the continuing appreciation of the Czech koruna exchange rate (CNB's inflation report from $2 / 2002$ to 4/2003). Then from the first quarter of 2004 to the third quarter of 2007 the inflation was moving more or less within the target band and later relatively close to the target value set by the CNB for this period. Since then inflation was shooting up and had peaked at the level of more than $7 \%$ in the first quarter of 2008 . According to the CNB (2000-2011), this rise was due to food prices, regulated prices as well as inflationary effect of the real economy (CNB's inflation report from 3/2007 to 3/2008). After that inflation fell sharply and ended up close to zeros in the second quarter of 2009. This fall was due to the drop in regulated prices and food prices and adjusted inflation excluding fuels. Since then inflation rose back and has been moving close to the target value set by CNB.

Figure 5

\section{Inflation Rate in the Czech Economy in 2001-2011}

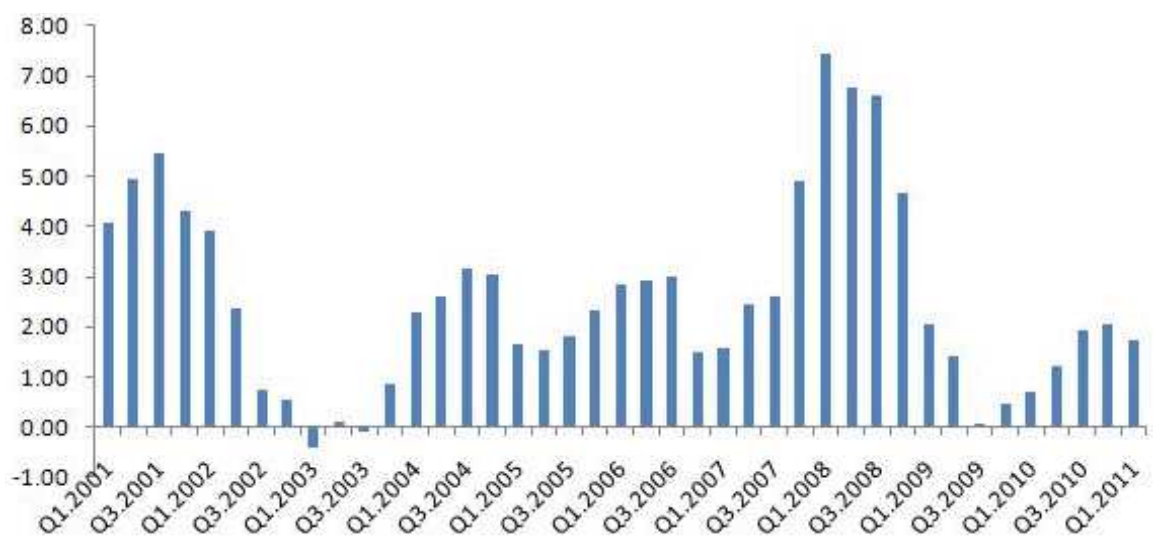

source: Czech Statistical Office

The development of the Czech economy in the examined period is shown in Figure 6. ${ }^{5}$ Since the beginning of the period the growth was mild and had been recovering from the recession in the previous period. This lethargic period led to the bottom in the third quarter in 2002 with the growth rate below $2 \%$ because of persisting weak external demand and the appreciation of the Czech koruna exchange rate. It was worsened further by the

5 Data on the growth rate of the Czech economy are from Czech Statistical Office database. They are annualized quarterly growth rates. 
damage caused by severe flooding in the Czech Republic. Then the economy picked up and enjoyed a relatively long booming period until the end of 2007. The buoyant growth in this period was credited to the external demand in the first half and to the household consumption and gross capital formation in the second half of this period. After that the economic growth slowed down and fell into deep recession as the result of the continuing global financial and economic crisis on external and domestic demand. Since 2010 the economy has mildly recovered from recession and kept having a modest growth pace up until the end of the examined period.

\section{Figure 6}

\section{The GDP Growth Rate of the Czech Economy in 2001-2011}

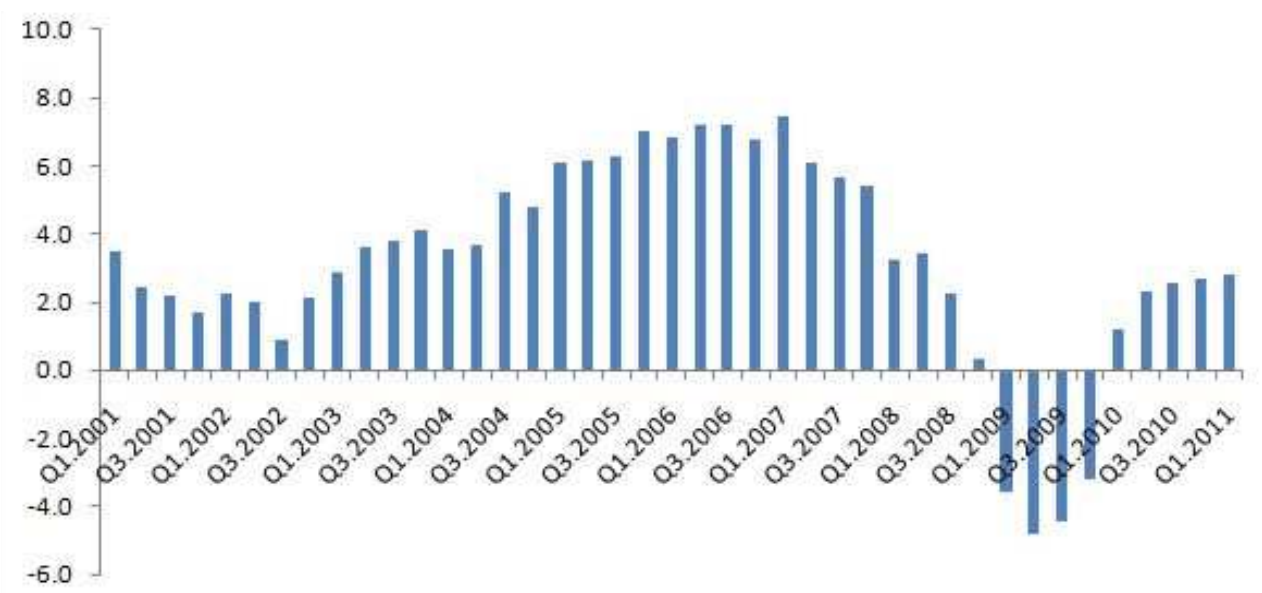

Source: Czech Statistical Office

With these two principal indicators on the Czech economy, we proceed to verify the monetary policy conducted by the CNB since 2000 . When doing so, we make two assumptions. First, we assume that the $\mathrm{CNB}$ would change the $2 \mathrm{~W}$ repo rate only once (if any) in a quarter though in reality there were four cases when the CNB changed its rate twice in a quarter during the examined period. Second, we suppose that if the interest rate needed to be changed, the CNB would do it at the end of a quarter. In reality, at that moment the CNB does not have the data on inflation and economic growth for the corresponding quarter yet, it has enough signals on the trend of these two variables to get some reasonably precise forecast on their values. The forecast values by definition of rational expectation are the actual values of the two variables for each quarter. Therefore, it can be considered, to some extent, to bear some feature of forward-looking reaction of the central bank.

In accordance with fuzzy control procedure presented in the previous part, we need to fuzzify the crisp numbers on inflation and growth. The determination of the membership values of GDP growth rate is quite simple. The growth rate of potential product of the Czech economy is calculated as the long-run average growth rate of the economy for 
the whole period since 2000 . This value is $3.05 \%$. We use the membership function for the GDP growth rate explained in the previous part. Converting data on inflation to its membership values is a bit more complicated since over the whole period the target value was not constant and was set differently. In 2000 and 2001, it was set as a target band for net inflation. For year 2000 the band was 3.5-5.5\%, in 2001 it was $2-4 \%$. For these 2 years we add $1 \%$ to the target band in order to use data on inflation measured by CPI. Therefore, for example, for 2000 if the inflation rate measured by CPI is in interval $(4.5,6.5)$ the membership values of the just rightness of inflation is 1 . This value decreases towards 0 when inflation lowers to 3 or increases to $7 \%$, respectively. If it is outside of interval $(3,7)$, the degree of rightness is 0 . The inflation is definitely not high if it is less than $6.5 \%$ and it is definitely high if it is higher than $8 \%$. If it is in interval from 6.5 to $8 \%$, the membership value can attain any value in interval $(0,1)$. The inflation is definitely low if it is less than $3.0 \%$ and it is definitely not low if it is higher than $4.5 \%$. If it is in interval $(3,4.5)$, the membership value will be in interval $(0,1)$. Similarly, the membership functions of inflation for year 2001 are constructed. Since 2002, the target band for inflation was set directly in CPI and in the period 2002-2005 the target interval was gradually lowered from $3-5 \%$ to $2-4 \%$. The target value of inflation for this period is the middle value which falls from 4 in the beginning to 3 at the end of the period. If inflation falls into the band, it is just right. If it is outside of the band in the range of $1 \%$, the membership value of just rightness is in interval $(0,1)$. If it is out of this range, the degree of rightness is 0 . On the contrary, if inflation is less than the lower bound of the band subtracted by 1 , the degree of lowness is 1 . If it is in interval (lower bound - 1 , lower bound), the corresponding degree of lowness will be in interval $(0,1)$. If it is higher than the lower bound, the membership value of lowness is 0 . By the same token, we construct the membership function of inflation for the case of highness.

Since 2006 the CNB has adopted a new inflation target set as a point target instead of the band target. For period 2006-2009 the target value was 3\% with a tolerance band of one percentage point in either direction. The membership functions are constructed as follows. If the inflation falls into interval of the target point and a half of a percentage point in either direction, it has the degree of rightness equal to 1 . This value will be in interval $(0,1)$ if inflation falls outside of this interval in range of $1 \%$ in both sides. The value of rightness is 0 if inflation lies outside of interval $(1.5,4.5)$. For the case of lowness, the membership value is 1 if inflation is less than 1.5. This value is in interval $(0,1)$ if inflation measured by CPI is in interval $(1.5,2.5)$. The degree of lowness is 0 if inflation is higher than 2.5. Similarly, the degree of highness is 0 if inflation is less than 3.5. This value will be in interval $(0,1)$ if inflation is in interval $(3.5,4.5)$ and it is 1 if inflation is higher than 4.5. From 2010 the target point set by the CNB is $2 \%$ and the membership functions are constructed exactly in the same way as presented in the previous part.

The membership values of inflation and economic growth then serve as inputs to equations (7), (8) and (9) to get the membership values for possible actions with interest rate. Then these fuzzy values are converted back to crisp values presenting the size of 
a change in the CNB's key interest rate. The conversion is followed by the center of gravity method shown in the previous part. As the CNB changes its interest rate in the multiple of a quarter of a percentage point, the calculated size of a change is rounded up (down) according to the following rule: if the calculated size of a change is less than $0.125 \%$, the eventual change will be 0 . If the calculated size of a change is in interval $(0.125,0.375)$, the eventual change will be $0.25 \%$. If the calculated size of a change is in interval $(0.375,0.625)$, the eventual change will be $0.5 \%$. If it is higher, the change will be $0.75 \%$.

\section{Alternative monetary policy rules}

To further examine the appropriateness of the monetary policy rule in the inflation targeting framework, we propose several alternatives. The first one is called the fighting inflation rule. In this case the only objective of the central bank is to keep the price level in the economy stable (stable price level need not mean no inflation at all). With fuzzy control approach the procedure is quite similar, it is only much simpler. Given the target value for inflation, we have to fuzzify only the actual inflation in the way explained in the previous section. We have just one rule which is:

Table 2

Monetary Policy Rules

\begin{tabular}{|c|c|c|c|}
\hline Inflation & Low & Just right & High \\
\hline Policy & decrease IR & do not change & increase IR \\
\hline
\end{tabular}

As we have only one rule, no combination of rules is needed and the membership values for manipulation with interest rate are the same as the membership values of three possible states of inflation. Finally, the size of a change in the key interest rate is determined by the same fashion as the case of inflation targeting. Other alternative are various variants of Taylor's rule. The first one is the original Taylor's rule (denoted as Taylor0). The other two come from the generalization of the original rule shown in (5). In one case we set the values for $\theta_{\pi}=\theta_{y}=\frac{1}{2}$ which means that the CNB puts equal weight on its two objectives (Taylor1). In the second case the values are set as follows: $\theta_{\pi}=1.5$ and $\theta_{y}=0.5$ which means the central bank puts more emphasis on taming inflation (Taylor2). In both cases, the value of $\theta_{i}$ is 0.8 and the value of $r^{*}=2$. The target value for inflation is the same as explained in the previous part. Calculated values are rounded up (down) in a similar fashion as in the case with fuzzy control procedure to get the eventual interest rate to be in the form with multiples of a quarter of a percentage point at the end. If the calculated values are negative, they are set to be equal to 0 .

The result of our verification is shown in Figures 7 and 8 as well as in Tables 3 and 4. From Figure 7 it is clear that fuzzy control approach can effectively deal with the objectives of monetary policy realized in the inflation targeting framework. In fact it is the closest line 
to the line of the CNB's actual policy. From the point of view of fuzzy control the CNB's actual policy in the examined period was oscillating between inflation targeting and pure fighting inflation. At times of mild inflation the CNB tried to support economic growth. When the growth is high, it would work hard to keep inflation in line with the inflation target it sets and fighting inflation is a kind of upper bound of the CNB's actual policy (except the beginning of the examined period). Sometimes the policy implemented by the CNB was more aggressive than the inflation targeting policy realized by fuzzy control approach. As far as the Taylor rule and its variants are concerned, from Figure 8, it is clear that these formulae cannot capture the actual development of the CNB's $2 \mathrm{~W}$ repo rate.

\section{Figure 7}

The Development of CNB 2W Repo Rate in 2000-2011, I

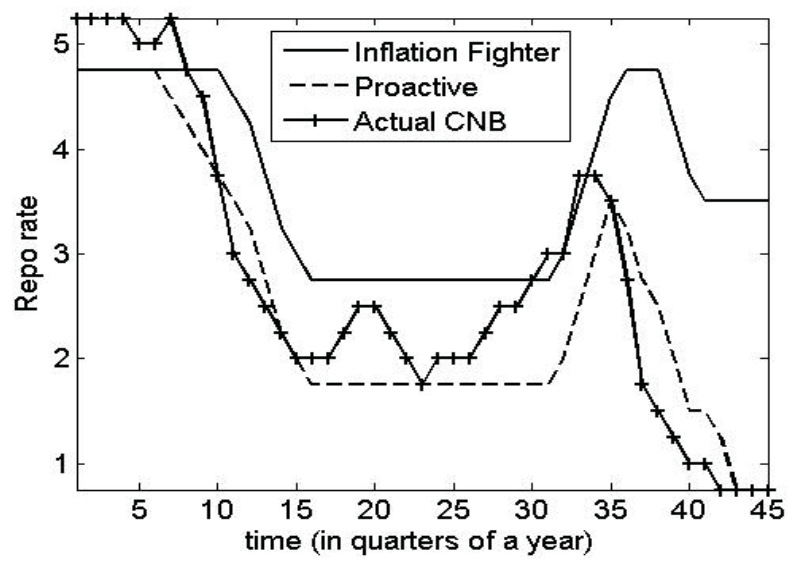

Source: Own calculations

The reason of the failure of the original Taylor rule is understandable because it was created for a different economy in a different period. As the whole, their failure comes from the fact that the policy interest rate is a linear function of deviations of inflation and economic growth from the target value for inflation and the long-run growth rate respectively. The size of the interest rate set by a central bank depends not only on the values of the parameters included in these formulae, but also on the size of deviations. Large deviations lead to extreme value of interest rate and following the Taylor rules strictly can lead to wild jumps of interest rate (see Table 4) which is in a sharp contrast to common practice of most central banks. They would make several smaller changes in interest rate rather than one big change. According to Woodford (1999) adjusting interest rates only gradually in response to changes in economic conditions is optimal since small but persistent changes in short-term interest rates in response to shocks allow a larger effect of monetary policy on long rates and hence upon aggregate demand, for a given degree of overall interest-rate variability.

Why does the monetary policy rule operated according to fuzzy control approach perform better than other approaches? The reason is very simple. Within the fuzzy control 
framework, the relationship between the interest rate and deviations of inflation and economic growth from the target value for inflation and the long-run growth rate can be formalized as follows:

$$
\Delta i_{t}=\mathrm{f}\left(\pi-\pi^{T A R}, y-y^{*}\right)
$$

where $\Delta i_{t}=i_{t}-i_{t-1}$, and $\mathrm{f}$ is a non-linear and bounded function. Similarly, Taylor rule can be expressed as follows:

$$
i_{t}=C+\theta_{\pi}\left(\pi-\pi^{T A R}\right)+\theta_{y}\left(y-y^{*}\right)
$$

where $C$ is a constant. As we see, the interest rate quantified by equation (12) is clearly a linear function of two arguments $\pi-\pi^{T A R}$ and $y-y^{*}$. As a linear function, it is unbounded. Therefore it is obvious that the Taylor rule is a special case of the monetary policy rule determined by fuzzy control approach.

This monetary rule can be also extended by other objectives targeted by a central bank. For an open economy, for example, the objective of the central bank may be a stable level of exchange rate. In the same fashion as the rule suggested by Taylor (2001), the deviation of the actual exchange rate from the targeted level becomes another variable of function (11). The procedure how to incorporate this variable into monetary rule based on fuzzy control approach will follow the same pattern as for variables inflation and economic growth shown above. The Czech National Bank has adopted a flexible exchange rate policy and has stuck to it roughly throughout the examined period. This fact was investigated by Paez-Farrell (2007), and recently by Frommel et al. (2011) and they found a declining emphasis of monetary policy on exchange rate. As a result, the rule based only on two inputs, which are inflation and economic growth for the Czech Republic, seems to be an appropriate one and the interest rate policy obtained by this rule is well in line with the actual CNB's policy as we have shown.

Figure 8

The Development of CNB 2W Repo Rate in 2000-2011, II

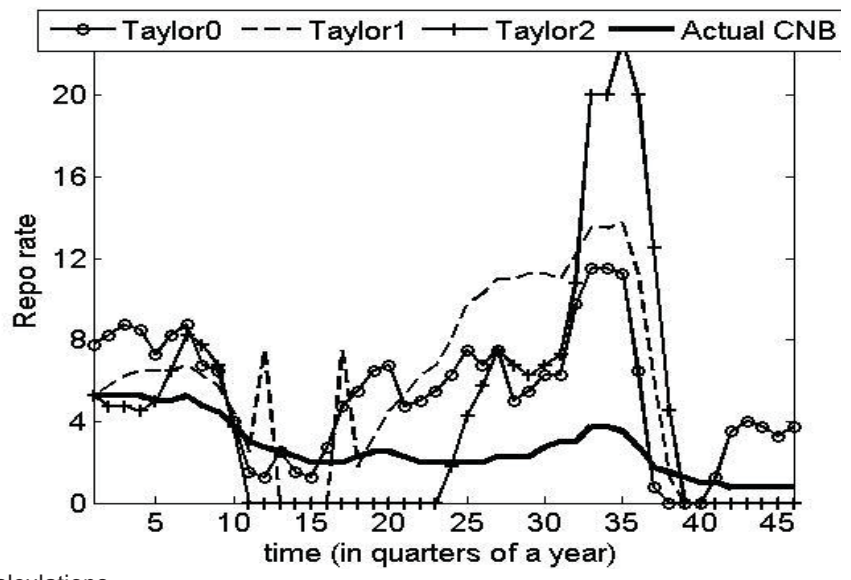

Source: Own calculations 


\section{Conclusion}

In this paper we have shown that fuzzy control can be applied to monetary policy in the inflation targeting regime. Qualitatively, most monetary policy rules are sensible and no-one argues against their validity. On the other hand, as the underlying mechanism controlling economic activities is not exactly quantifiable, running monetary policy by a central bank still is an intuitive matter rather a mathematically well-defined control problem. As such, the way how central banks set their policy interest rate still is a mystery. To solve this issue, we propose the fuzzy control approach as a rule for monetary policy in the inflation targeting framework. The fuzzy control rule is capable of converting well-accepted qualitative monetary policy principles to quantitative response in terms of the size of the monetary policy interest rate of a central bank. In comparison with the fuzzy control approach, the widely used monetary rule suggested by Taylor (1993) is just a special case. Taylor rule is a linear and unbound function of deviations of controlled economic variables from their desired objectives, its results depend on the externally determined values of its coefficients as well as the sizes of deviations. Following Taylor rule would lead to such policy which is in contrast with how central banks conduct monetary policy. On the contrary, implementing monetary policy according to fuzzy control rule would lead to a result which is in line with common central bank practice as we show in the case of the Czech National Bank in period from 2000 to 2011.

Though fuzzy control method is relatively new, it has already had widespread application in technical disciplines. On the other hand, its application to economic controlling is very limited. In fact, we have found it only in two works (Georgescu, 2002 and Keller, 2009) on the matter. Therefore it surely deserves more attention. Further, in this paper we have used a model-free approach to quantify the monetary decision of the Czech National Bank. Fuzzy control approach can be extended to the higher number of controlled variables. It would be also very interesting to combine the fuzzy control technique with a DSGE model as when modelling an economy, the Taylor rule is often used since a reaction function of central banks nowadays to the changes in the economy. As was already shown, monetary policy is not exactly operated according to the Taylor rule, so it would help us to see whether the fuzzy control approach is capable of improving the outputs of DSGE model. 


\section{Appendix}

Table 3

The Calculated and Actual Levels of 2W Repo Rate

\begin{tabular}{|c|c|c|c|c|c|c|}
\hline Year & Quarter & Target & Fight Infl. & Actual level & Date of change & Add. change \\
\hline 2000 & 1 & 4.75 & 4.75 & 5.25 & - & - \\
\hline- & 2 & - & 4.75 & - & - & - \\
\hline- & 3 & - & 4.75 & - & - & - \\
\hline- & 4 & - & 4.75 & - & - & - \\
\hline 2001 & 1 & - & 4.75 & 5.00 & 22.3. & - \\
\hline- & 2 & 4.75 & 4.75 & - & - & - \\
\hline- & 3 & 4.5 & 4.75 & 5.25 & 17.7. & - \\
\hline- & 4 & 4.25 & 4.75 & 4.75 & 30.11. & - \\
\hline 2002 & 1 & 4.00 & - & 4.50 & 22.1 & 4.25 (1.2.) \\
\hline- & 2 & 3.75 & 4.75 & 3.75 & 26.4. & - \\
\hline- & 3 & 3.5 & 4.5 & 3.00 & 26.7. & - \\
\hline- & 4 & 3.25 & 4.25 & 2.75 & 1.11. & - \\
\hline 2003 & 1 & 2.75 & 3.75 & 2.50 & 31.1. & - \\
\hline- & 2 & 2.25 & 3.25 & 2.25 & -26.6. & - \\
\hline- & 3 & 2.00 & 3.00 & 2.00 & 1.8. & - \\
\hline- & 4 & 1.75 & 2.75 & - & - & - \\
\hline 2004 & 1 & - & 2.75 & - & - & - \\
\hline- & 2 & - & 2.75 & 2.25 & 25.6. & - \\
\hline- & 3 & - & 2.75 & 2.50 & 27.8. & - \\
\hline- & 4 & - & 2.75 & - & - & - \\
\hline 2005 & 1 & - & 2.75 & 2.25 & 28.1. & - \\
\hline- & 3 & - & 2.75 & - & - & - \\
\hline- & 4 & - & 2.75 & 2.00 & 31.10. & - \\
\hline 2006 & 1 & - & 2.75 & - & - & - \\
\hline- & 2 & - & & $2.75-$ & - & - \\
\hline- & 3 & - & 2.75 & 2.25 & 28.7. & 2.50 (29.9.) \\
\hline- & 4 & - & 2.75 & - & - & - \\
\hline 2007 & 1 & - & 2.75 & - & - & - \\
\hline- & 2 & - & 2.75 & 2.75 & 1.6. & - \\
\hline- & 3 & 1.75 & 2.75 & 3.00 & 27.7. & - \\
\hline- & 4 & 2.00 & 3.00 & - & - & - \\
\hline 2008 & 1 & 2.50 & 3.50 & 3.75 & 8.2. & - \\
\hline- & 2 & 3.00 & 4.00 & - & - & - \\
\hline
\end{tabular}


Table 3 - Continuation

\begin{tabular}{|c|c|c|c|c|c|c|}
\hline- & 3 & 3.50 & 4.50 & 3.50 & 8.8. & \\
\hline- & 4 & 3.25 & 4.75 & 2.75 & 7.11. & 2.25 (8.12.) \\
\hline 2009 & 1 & 2.75 & 4.75 & 1.75 & 6.2. & - \\
\hline- & 2 & 2.50 & 4.75 & 1.50 & 11.5. & - \\
\hline- & 3 & 2.00 & 4.25 & 1.25 & 7.8. & - \\
\hline- & 4 & 2.00 & 3.75 & 1.00 & 17.12. & - \\
\hline 2010 & 1 & 1.50 & 3.75 & - & - & - \\
\hline- & 2 & 1.50 & 3.75 & 0.75 & 7.5. & - \\
\hline- & 3 & 1.25 & 3.75 & - & - & - \\
\hline- & 4 & 0.75 & 3.75 & - & - & - \\
\hline 2011 & 1 & 0.75 & 3.75 & - & - & - \\
\hline- & 2 & 0.75 & 3.75 & - & & - \\
\hline
\end{tabular}


Table 4

The Taylor-type Calculated Levels and Actual Level of 2W Repo Rate

\begin{tabular}{|c|c|c|c|c|c|c|}
\hline Year & Quarter & Taylor0 & Taylor1 & Taylor2 & Actual level & Date of change \\
\hline 2000 & 1 & 7.75 & 5.25 & 5.25 & 5.25 & - \\
\hline- & 2 & 8.25 & 5.75 & 4.75 & - & - \\
\hline- & 3 & 8.75 & 6.25 & 4.75 & - & - \\
\hline- & 4 & 8.5 & 6.50 & 4.50 & - & - \\
\hline 2001 & 1 & 7.25 & 6.50 & 5.00 & 5.00 & 22.3. \\
\hline- & 2 & 8.25 & 6.50 & 6.50 & - & - \\
\hline- & 3 & 8.75 & 6.75 & 8.25 & 5.25 & 17.7. \\
\hline- & 4 & 6.75 & 6.25 & 7.75 & 4.75 & 30.11. \\
\hline 2002 & 1 & 6.50 & 5.75 & 6.75 & 4.50 & 22.1. \\
\hline- & 2 & 4.00 & 4.50 & 3.75 & 3.75 & 26.4. \\
\hline- & 3 & 1.50 & 2.50 & 0.00 & 3.00 & 26.7. \\
\hline- & 4 & 1.25 & 7.5 & 0.00 & 2.75 & 1.11. \\
\hline 2003 & 1 & 2.50 & 0.0 & 0.00 & 2.5 & 31.1. \\
\hline- & 2 & 1.50 & 0.00 & 0.0 & 2.25 & -26.6 \\
\hline- & 3 & 1.25 & 0.00 & 0.0 & 2.00 & 1.8. \\
\hline- & 4 & 2.75 & 0.00 & 0.0 & - & - \\
\hline 2004 & 1 & 4.75 & 7.50 & 0.0 & - & - \\
\hline- & 2 & 5.50 & 1.75 & 0.0 & 2.25 & 25.6. \\
\hline- & 3 & 6.50 & 3.25 & 0.0 & 2.50 & 27.8. \\
\hline- & 4 & 6.75 & 4.50 & 0.00 & - & - \\
\hline 2005 & 1 & 4.75 & 5.25 & 0.00 & 2.25 & 28.1. \\
\hline- & 2 & 5.00 & 6.25 & 0.0 & 2.00 & 1.4. \\
\hline- & 3 & 5.50 & 6.75 & 0.0 & - & - \\
\hline- & 4 & 6.25 & 8.00 & 1.75 & 2.00 & 31.10 \\
\hline 2006 & 1 & 7.50 & 9.75 & 4.25 & - & - \\
\hline- & 2 & 6.75 & 10.25 & 5.75 & - & - \\
\hline- & 3 & 7.50 & 11.00 & 7.50 & 2.25 & 28.7. \\
\hline- & 4 & 5.00 & 11.00 & 6.75 & - & - \\
\hline 2007 & 1 & 5.50 & 11.25 & 6.25 & - & - \\
\hline- & 2 & 6.25 & 11.25 & 6.75 & 2.75 & 1.6. \\
\hline- & 3 & 6.25 & 11.00 & 7.25 & 3.00 & 27.7. \\
\hline- & 4 & 9.75 & 12.25 & 10.75 & - & - \\
\hline 2008 & 1 & 11.50 & 13.50 & 20.00 & 3.75 & 8.2. \\
\hline- & 2 & 11.50 & 13.50 & 20.00 & - & - \\
\hline- & 3 & 11.25 & 13.75 & 22.75 & 3.50 & 8.8. \\
\hline- & 4 & 6.50 & 11.25 & 20.00 & 2.75 & 7.11. \\
\hline
\end{tabular}


Table 4 - Continuation

\begin{tabular}{|c|c|c|c|c|c|c|}
\hline 2009 & 1 & 0.75 & 6.25 & 12.50 & 1.75 & 6.2. \\
\hline- & 2 & 0.0 & 1.25 & 4.50 & 1.5 & 11.5. \\
\hline- & 3 & 0.0 & 0.0 & 0.0 & 1.25 & 7.8. \\
\hline- & 4 & 0.0 & 0.0 & 0.0 & 1.00 & 17.12. \\
\hline 2010 & 1 & 1.25 & 0.0 & 0.0 & - & - \\
\hline- & 2 & 3.50 & 0.0 & 0.0 & 0.75 & 7.5. \\
\hline- & 3 & 4.0 & 0.0 & 0.0 & - & - \\
\hline- & 4 & 3.75 & 0.0 & 0.0 & - & - \\
\hline 2011 & 1 & 3.25 & 0.0 & 0.0 & - & - \\
\hline- & 2 & 3.75 & 0.0 & 0.0 & - & - \\
\hline
\end{tabular}




\section{References}

Arlt, J., Mandel, M. (2012), "Is It Possible to Predict the CNB Repo Rate on the Basis of Backward Looking Monetary Rule?" Politická ekonomie, Vol. 21, No. 4.

Bernanke, B. S., Laubach, T., Mishkin, F. S., Posen, A. S. (1999), Inflation Targeting. New Jersey: Princeton University Press, Princeton.

Czech National Bank (2000-2011), Inflation Reports. Czech Republic: Czech National Bank.

Friedman, M. (1968), "The Role of Monetary Policy." American Economic Review, Vol. 58, No. 1 , pp. $1-17$.

Frommel, M., Garabedian, G., Schopert, V. (2011), "Monetary Policy Rules in Central and Eastern Europe: Does the Exchange Rate Matter?" Journal of Macroeconomics, Vol. 33, No. 4, pp. 807-818.

Georgescu, V. (2002), "Capturing and Tuning Nonlinear Characteristics of Economic Stabilization Systems by Fuzzy Control Technique." Computational Economics, Vol. 19, No. 3, pp. 247-271.

Jantzen, J. (2007), Foundation of Fuzzy Control. West Sussex: Wiley.

Keller, A. A. (2009), "Fuzzy Control of Macroeconomic Models." International Journal of Mathematical and Computer Sciences, Vol. 5, No. 2, pp. 115-124.

Mamdani, E. H., Assilian, S. (1975), "An Experiment in Linguistic Synthesis with a Fuzzy Logic Controller." International Journal of Man-Machine Studies, Vol. 7, No. 1, pp. 1-13.

McCallum, B. T. (2000), "Alternative Monetary Policy Rules: A Comparison with Historical Settings for the United States, the United Kingdom, and Japan." NBER Working Paper No. 7725.

Novák, V. (2000), Základy fuzzy modelování. Praha: BEN Technická literatura.

Orphanides, A. (2001), "Monetary Policy Rules Based on Real-Time Data." American Economic Review, Vol. 91, No. 4, pp. 964-985.

Orphanides, A. (2003), "Historical Monetary Policy Analysis and the Taylor Rule." Journal of Monetary Economics, Vol. 50, No. 5, pp. 983-1022.

Paez-Farrell, J. (2007), "Understanding Monetary Policy in Central European Countries Using Taylortype Rules: The Case of the Visegrad Four." Economics Bulletin, Vol. 5, No. 3, pp. 1-11.

Svensson, L. E. O. (2003), "What Is Wrong with Taylor Rules? Using Judgment in Monetary Policy through Targeting Rules." Journal of Economic Literature, Vol. 41, No. 2, pp. 226- 277.

Taylor, J. B. (1993), "Discretion versus Policy Rules in Practice." Carnegie-Rochester Conference Series on Public Policy, Vol. 39, No. 1, pp. 195-214.

Taylor, J. B. (1998), "The Robustness and Efficiency of Monetary Policy Rules as Guidelines for the Interest Rate Setting by the European Central Bank." Journal of Monetary Economics, Vol. 43, No. 3, pp. 655-79.

Taylor, J. B. (2001), "The Role of the Exchange Rate in Monetary Policy Rules." American Economic Review, Vol. 91, No. 2, pp. 263-267.

Walsh, C. E. (2010), Monetary Theory and Policy, 3rd Ed. Massachusetts: MIT Press.

Wicksell, K. (1936), Interest and Prices, London: Macmillan.

Woodford, M. (1999), “Optimal Monetary Policy Inertia." NBER Working Paper No. 7261.

Woodford, M. (2001), "The Taylor Rule and Optimal Monetary Policy." The American Economic Review, Vol. 91, No. 2, pp. 232-237. 